\title{
Cinética de degradação ruminal de silagem de capim-elefante com diferentes níveis de jaca e raspa de mandioca
}

\section{Ruminal degradation kinetics of elephant grass silage with different levels of jack fruit and cassava scraping}

\author{
João Ricardo Rebouças Dórea ${ }^{1 *}$; Juliana Silva Oliveira²; Edson Mauro Santos²; \\ Anderson de Moura Zanine ${ }^{3}$; Thiago Carvalho da Silva \\ Marina de Arruda Camargo Danés ${ }^{5}$; André Luiz Custódio Franco ${ }^{6}$; \\ Vinícius Nunes de Gouvêa ${ }^{7}$; Ivone Yurika Mizubuti ${ }^{8}$
}

\section{Resumo}

Objetivou-se com este estudo avaliar a cinética de degradação ruminal in situ em dois experimentos, os quais utilizaram níveis de jaca desidratada $(0,5,10$ e $15 \%$ na matéria natural $)$ e raspa de mandioca $(0,7$, 15 e $30 \%$ na matéria natural) na ensilagem do capim elefante. Os dois experimentos foram realizados no Departamento de Zootecnia da Universidade Federal de Viçosa, no mesmo período e seguiram o mesmo protocolo. Foi utilizado um modelo misto no qual foi considerado o efeito aleatório de experimento e efeitos fixos de tratamento e interação tratamento com experimento. Amostras de $3 \mathrm{~g}$ de silagens de cada tratamento foram incubadas no rúmen de três novilhas por períodos de $0,3,6,12,24,36,48,72$, 96 e 120 horas. Em seguida avaliou-se a fração potencialmente degradável (B), a fração indigestível (I), taxa de degradação da fração potencialmente degradável (c), lag time, e degradabilidade efetiva (DE) a 2, 5 e $8 \%$ /hora. Não houve efeito da inclusão de aditivos na ensilagem do capim elefante sobre a degradabilidade efetiva ( $\mathrm{P}>0,05)$, apresentando intercepto em 47,$7 ; 40,7$ e $34,9 \%$ para as taxas de passagem de 2, 5 e $8 \% / \mathrm{h}$, respectivamente. Houve efeito da interação experimentos com tratamentos $(\mathrm{P}<0,05)$, o que demonstra que as inclusões de aditivos à silagem de capim-elefante promoveram diferentes benefícios dentro de cada experimento. A inclusão de jaca desidratada aumentou linearmente $(\mathrm{P}<0,05)$ a degradação da fração potencialmente degradável da FDN. A inclusão de jaca desidratada e raspa de mandioca às silagens de capim elefante promovem aumento da fração potencialmente degradável da fibra e redução da fração indigestível.

Palavras-chave: Aditivo, co-produto, degradabilidade, fermentação ruminal

\footnotetext{
${ }^{1}$ Discente de Doutorado em Ciência Animal e Pastagem, Dept ${ }^{\mathrm{o}}$ de Zootecnia, Universidade de São Paulo, USP, Piracicaba. E-mail: joaodorea@hotmail.com

${ }^{2}$ Profs. Adjunto, Dept ${ }^{\circ}$ de Zootecnia, Universidade Federal da Paraíba, UFPB, Areia, PB. E-mail: oliveirajs@yahoo.com.br; edson@cca.ufpb.br

${ }^{3}$ Prof. Adjunto, Dept ${ }^{\circ}$ de Zootecnia, Universidade Federal do Mato Grosso, UFMT, Rondonópolis, MT. E-mail: andersonzanine@ ufmt.br

${ }^{4}$ Discente de Doutorado em Zootecnia, Dept ${ }^{\circ}$ de Zootecnia, Universidade Federal de Viçosa, UFV, Viçosa, MG. E-mail: thiago.c.silva@ufv.br

${ }^{5}$ Discente de Doutorado em Animal Science, University of Wisconsin, UW, Madison, WI. E-mail: mdanes@wisc.edu

${ }^{6}$ Discente de Doutorado em Solos e Nutrição de Plantas, Universidade de São Paulo, USP, Piracicaba, SP. E-mail: andrefranco@ usp.br

${ }^{7}$ Discente de Mestrado do Dept ${ }^{\mathrm{o}}$ de Zootecnia em Ciência Animal e Pastagem, USP, Piracicaba, SP. E-mail: gouveavin@hotmail. com

${ }^{8}$ Prof $^{\mathrm{a}}$ Associado, Dept ${ }^{\mathrm{o}}$ de Zootecnia, Universidade Estadual de Londrina, UEL, Londrina, PR. Bolsista de Produtividade do CNPq.E-mail: mizubuti@uel.br

* Autor para correspondência
} 


\begin{abstract}
The objective of this study was to evaluate in situ ruminal degradation kinetics in two experiments, which different levels of dehydrated jackfruit $(0,5,10$ and $15 \%$ in natural matter) and cassavas scraping $(0,7,15$ and $30 \%$ in natural matter) in the elephant grass silage, were used. The two experiments were carried out at the Department of Animal Science, Federal University of Viçosa, Brazil, in the same period and followed the same protocol. A mixed model was used, in which was considered random effect of experiment and fixed effects of experimental treatment and interaction among treatments with experiments. Samples of $3 \mathrm{~g}$ of each silage treatment were incubated in the rumen of three steers by periods of $0,3,6,12$, 24, 36, 48, 72, 96 and 120 hours. Then, the potentially degradable fraction(B), indigestible fraction (I), degradation rate of potentially degradable fraction (c), lag time, and effective degradability (ED) at 2, 5 and $8 \%$ per hour, were evaluated. No effect of addition of additives in ensiling of Napier grass for the effective degradability $(\mathrm{P}>0.05)$ was observed, presenting an intercept at $47.7,40.7$ and $34.9 \%$ for the passage rates of 2,5 and $8 \% / \mathrm{h}$ respectively. There were significant interaction among experiments with treatments $(\mathrm{P}<0.05)$, which demonstrates that the inclusion of additives in elephant grass silage promoted different benefits within each experiment. The inclusion of jackfruit increased linearly $(\mathrm{P}<0.05)$ the degradation of potentially degradable fraction of NDF. The inclusion of jackfruit dehydrated and cassava scrapings to the elephant grass silage promotes the increase of the potentially degradable fraction of fiber and the reduction of indigestible fraction.
\end{abstract}

Key words: Additive, by-product, degradability, ruminal fermentation

\section{Introdução}

O capim-elefante (Pennisetum purpureum Schum.) possui alto potencial de produção de matéria seca (MS), com bom valor nutritivo quando bem manejado (SANTOS et al., 2006), o que torna esta forrageira uma excelente opção para ensilagem. No entanto, o valor nutritivo mais adequado coincide com a fase de crescimento quando a planta é jovem, e neste período o elevado teor de umidade associado ao poder tamponante e à baixa população inicial de bactérias láticas pode gerar fermentações secundárias (ANDRADE; MELOTTI; LAÉRCIO, 2004). Como consequência, as perdas de nutrientes na forma de gases, devido a fermentações secundárias, e na forma de efluente, devido ao excesso de umidade são comuns em silagens destes capins (SANTOS et al., 2006; ZANINE et al., 2006).

Diante dessa realidade o uso de aditivos com elevados teores de matéria seca (MS) e adequado valor nutricional, além de fornecer carboidratos para fermentação, torna-se uma boa opção para reduzir as perdas por efluentes, que carreiam nutrientes altamente digestíveis, açúcares e ácidos orgânicos, diminuindo o valor nutritivo da silagem (ZANINE et al., 2006). Desta forma, aditivos como a raspa de mandioca, que é um subproduto da indústria de farinha, é capaz de elevar o teor de MS, e fornecer carboidratos para a fermentação do material ensilado, com baixo custo de aquisição, melhorando a conservação dos nutrientes da silagem (ZANINE et al., 2010). Outro aditivo com comprovada capacidade de melhorias na fermentação da silagem de capim-elefante é a jaca desidratada (Artocarpus heterophyllus Lam.), pois este aditivo eleva o teor de MS e reduz as perdas por gases e efluentes, além de aumentar a fermentação lática e diminuir a proteólise no processo fermentativo (SANTOS et al., 2008). No entanto, é importante que os benefícios do uso de aditivos não permaneçam somente no processo fermentativo, mas que apresentem contribuições 
benéficas na fermentação ruminal, melhorando o valor nutritivo da silagem e melhorando o consumo voluntário e desempenho animal. Assim, tornase necessário estudar os efeitos dos aditivos não só na qualidade da conservação de forragem, mas também como estes aditivos poderão contribuir com a cinética de fermentação ruminal.

Considerando os benefícios gerados dos aditivos no processo de ensilagem, objetivou-se avaliar a cinética de fermentação ruminal in situ das silagens de capim-elefante com diferentes níveis de raspa de mandioca e de jaca desidratada.

\section{Material e Métodos}

O experimento foi realizado no Departamento de Zootecnia da Universidade Federal de Viçosa, localizada no município de Viçosa-MG. A cidade de Viçosa está situada a $20^{\circ}$ e $45^{\prime}$ de latitude sul, $42^{\circ}$ e 51'de longitude oeste e $657 \mathrm{~m}$ de altitude, apresentando precipitação média anual de 1341 $\mathrm{mm}$, dos quais cerca de $86 \%$ ocorrem nos meses de outubro a março.

O capim utilizado nos dois experimentos foi oriundo da área experimental do setor de Agrostologia, de uma capineira já implantada, 50 dias após o corte de uniformização a $20 \mathrm{~cm}$ do solo. A jaca foi obtida em propriedades rurais da região sul da Bahia, picada em máquina forrageira estacionária e, posteriormente, desidratada por um período de 48 horas em barcaças utilizadas para secagem de amêndoas de cacau. A raspa de mandioca foi obtida em indústria de farinha na região sul da Bahia.
O delineamento experimental foi o inteiramente casualizado, com quatro tratamentos para os dois experimentos, sendo o experimento 1: silagem de capim-elefante; silagem de capim-elefante $+5 \%$ de jaca desidratada; silagem de capim-elefante $+10 \%$ de jaca desidratada e silagem de capim-elefante $+15 \%$ de jaca desidratada, com 4 repetições por tratamento, e o experimento 2: silagem de capimelefante; silagem de capim-elefante $+7 \%$ de raspa de mandioca; silagem de capim-elefante $+15 \%$ de raspa de mandioca e silagem de capim-elefante + $30 \%$ de raspa de mandioca, com 4 repetições por tratamento. Os níveis de jaca e raspa de mandioca foram definidos com base na matéria natural.

Os silos experimentais foram confeccionados, utilizando-se baldes de aproximadamente 6 litros, vedados e com uma válvula de Bunsen adaptada em sua tampa, para permitir o escape dos gases oriundos da fermentação. No fundo de cada silo foi colocado $1 \mathrm{~kg}$ de areia, separados da forragem por uma camada de tecido de algodão, de maneira que fosse possível medir a quantidade de efluentes retida. O capim foi cortado para ensilagem em máquina forrageira estacionária, com tamanho de partícula de aproximadamente $1,5 \mathrm{~cm}$ e compactado com soquetes de madeira. Os silos foram abertos 40 dias após a ensilagem.

As amostras da silagem após abertura dos silos (aproximadamente $500 \mathrm{~g}$ ) foram pré-secos para determinação dos teores de matéria seca (MS), proteína bruta (PB), fibra em detergente neutro (FDN), fibra em detergente ácido (FDA) e hemicelulose (HEM) (Tabela 1), segundo metodologias descritas por Silva e Queiroz (2002). 
Tabela 1. Valores de matéria seca (MS), proteína bruta (PB), fibra em detergente neutro (FDN), fibra em detergente ácido (FDA) e hemicelulose (HEM) das silagens utilizadas nos experimentos 1 e 2.

\begin{tabular}{lcrrrrrr}
\hline & & \multicolumn{3}{c}{ Experimento 1 } & \multicolumn{3}{c}{ Experimento 2 } \\
\cline { 3 - 7 } & Controle & \multicolumn{3}{c}{ Níveis de jaca (\% na MN*) } & \multicolumn{1}{c}{ Níveis de raspa de mandioca (\% na MN) } \\
\cline { 3 - 7 } & & \multicolumn{1}{c}{5} & \multicolumn{1}{c}{10} & \multicolumn{1}{c}{15} & \multicolumn{1}{c}{15} & \multicolumn{1}{c}{30} \\
\hline MS (\%) & 18,2 & 21,9 & 22,4 & 24,6 & 24,2 & 28,3 & 32,6 \\
PB (\%MS) & 5,7 & 6,7 & 7,1 & 6,8 & 5,9 & 4,9 & 4,3 \\
FDN (\%MS) & 66,1 & 62,2 & 55,4 & 51,4 & 54,8 & 47,2 & 41,4 \\
FDA (\%MS) & 49,2 & 46,4 & 41,2 & 37,7 & 39,6 & 32,8 & 27,4 \\
HEM (\%MS & 16,9 & 15,7 & 37,7 & 13,6 & 15,2 & 14,3 & 13,9 \\
\hline
\end{tabular}

* MN= matéria natural.

Fonte: Elaboração dos autores.

Para a incubação in situ, foram utilizados três bovinos fistulados no rúmen, com peso vivo médio de $400 \mathrm{~kg}$, mantidos em pastagens de Brachiaria decumbens. As amostras da silagem foram présecas em estufa de ventilação forçada $\left(65^{\circ} \mathrm{C}\right.$ por 72 horas), moídas em peneiras com crivos de 2 $\mathrm{mm}$ e colocadas em sacos tipo F57 da ANKOM, respeitando a relação próxima de $20 \mathrm{mg}$ de $\mathrm{MS} / \mathrm{cm}^{2}$ de área superficial do saco.

Os períodos de incubação corresponderam aos tempos de $0,3,6,12,24,36,48,72,96$ e 120 horas, sendo os sacos colocados em ordem inversa, para serem retirados todos ao mesmo tempo, promovendo, dessa forma, lavagem uniforme do material por ocasião da retirada do rúmen. Após o período de incubação, os sacos de náilon foram lavados em água corrente até que esta se apresentasse limpa, procedendo-se, então, a secagem, e posterior determinação dos teores de FDN, segundo metodologia descrita por Van Soest e Robertson (1985).

A estimativa de degradação ruminal da FDN foi efetuada através do PROC NLIN do programa estatístico SAS (2003), segundo a equação proposta por Mertens e Loften (1980): Y = B* $\left.\left.\exp ^{-c(t-L a g}\right)\right)+I$, em que: B é a fração potencialmente degradável; c é a taxa de degradação da fração $\mathrm{B}$, lag é o lag time, t é o tempo de incubação e I é a fração indigestível da fibra.

A degradabilidade efetiva foi analisada segundo
Mertens e Loften (1980, segundo a seguinte equação: $\mathrm{DE}=\left(\mathrm{B} * \exp ^{\left(-\mathrm{k}^{*} \mathrm{Lag}\right)} * \mathrm{c}\right) /(\mathrm{c}+\mathrm{k})$, onde $\mathrm{k}$ é taxa de passagem, a qual foi considerada 2,5 e $8 \%$ por hora.

Os parâmetros estimados para os dois experimentos foram analisados juntos por meio de um modelo misto no qual foram considerados os efeitos fixos de níveis de inclusão do aditivo e fonte de aditivo (jaca ou raspa de mandioca) e a interação entre eles, bem como o efeito aleatório de experimento. Os dois experimentos foram realizados no mesmo período, com a mesma forragem, utilizando exatamente o mesmo protocolo. Quando algum parâmetro foi significativo $(\mathrm{P}<0,05)$ para o efeito da interação, foi feita uma equação de regressão para os níveis dentro de cada fonte de aditivo. O modelo misto foi realizado através do PROC MIXED, e as equações de regressão através do PROC REG, do programa estatístico SAS.

Obrigatoriamente, o conjunto de dados foi testado antes da análise geral final, na intenção de assegurar que todas as premissas da análise de variância (aditividade do modelo, independência dos erros, normalidade dos dados e homocedasticidade) estivessem sendo respeitadas.

\section{Resultados e Discussão}

$\mathrm{Na}$ Tabela 2 encontram-se os valores médios 
dos parâmetros de cinética de degradação ruminal da fibra em detergente neutro (FDN): fração potencialmente degradável (B), fração indigestível
(I), lag time (Lag), taxa de degradação da fração B (c) e degradabilidade efetiva (DE) a 2,5 e $8 \%$ por hora, para os dois experimentos.

Tabela 2. Valores médios da fração potencialmente degradável (B, \%), indigestível (I, \%), taxa de degradação (c, hora1), Lag time (Lag, hora) e degradabilidade efetiva (DE) a 2, 5 e $8 \%$ por hora (DE2\%, DE5\% e DE8\%).

\begin{tabular}{|c|c|c|c|c|c|c|c|c|c|c|}
\hline & \multirow{2}{*}{$\begin{array}{c}\text { Controle } \\
0 \\
\end{array}$} & \multicolumn{3}{|c|}{ Experimento 1} & \multicolumn{3}{|c|}{ Experimento 2} & \multirow{2}{*}{$\mathrm{NA}^{1}$} & \multirow{2}{*}{$\mathrm{NA}^{*} \mathrm{FA}^{2}$} & \multirow{2}{*}{$\mathrm{EPM}^{3}$} \\
\hline & & 5 & 10 & 15 & 7 & 15 & 30 & & & \\
\hline B & 52,99 & 55,07 & 55,4 & 57,77 & 50,24 & 51,19 & 60,08 & $*$ & $*$ & 1,42 \\
\hline I & 45,52 & 35,96 & 45,95 & 49,7 & 44,03 & 40,17 & 36,8 & $*$ & $*$ & 1,42 \\
\hline $\mathrm{C}$ & 0,0383 & 0,0413 & 0,0508 & 0,0538 & 0,037 & 0,0324 & 0,0445 & ns & * & 0,001 \\
\hline Lag & 5,46 & 3,12 & 4,08 & 7,99 & 4,59 & 2,99 & 3,33 & ns & * & 1,14 \\
\hline DE2\% & 47,57 & 51,75 & 51,11 & 49,28 & 45,9 & 48,38 & 56,22 & $*$ & ns & 2,05 \\
\hline DE5\% & 40,57 & 47,15 & 45,24 & 38,85 & 40,15 & 44,6 & 50,91 & ns & ns & 3,11 \\
\hline DE $8 \%$ & 34,68 & 42,97 & 40,06 & 30,64 & 35,19 & 41,3 & 46,11 & $\mathrm{~ns}$ & ns & 3,98 \\
\hline
\end{tabular}

${ }^{1}$ Nível do aditivo; ${ }^{2}$ Interação nível do aditivo $\mathrm{x}$ fonte do aditivo; ${ }^{3}$ Erro padrão da média.

* = significativo $(\mathrm{P}<0,05) ; \mathrm{ns}=$ não significativo $(\mathrm{P}>0,05)$.

Fonte: Elaboração dos autores.

Houve efeito da interação dos níveis com as fontes de aditivos $(\mathrm{P}<0,05)$, o que demonstra que as inclusões de aditivos à silagem de capim-elefante promoveram diferentes benefícios dentro de cada fonte utilizada (Tabela 2). A inclusão de jaca aumentou linearmente $(\mathrm{P}<0,05)$ a degradação da fração potencialmente degradável da FDN (Tabela 3). Até o nível de $10 \%$ de inclusão de jaca, o aumento na fração potencialmente digestível pode estar associado com a redução no tempo de colonização (Lag time), fator ao qual se atribui o aumento da degradação de FDN (MERTENS; LOFTEN, 1980; LARDY et al., 2004). No entanto, não era esperado o aumento do Lag time no nível de $15 \%$ de inclusão, uma vez que a fração B continuou aumentando neste nível (Figura 1). Este fato pode ser explicado pelo aumento linear da taxa de degradação $(\mathrm{P}<0,05)$, partindo de $3,83 \% / \mathrm{h}$ e chegando a $5,38 \% / \mathrm{h}$, o que possivelmente aumentou a extensão de degradação da fibra, mesmo com um maior tempo gasto para colonização das partículas, do tratamento com $15 \%$ de jaca em relação ao controle. 
Figura 1. Degradação ruminal in situ da fibra em detergente neutro (FDN) da silagem de capim elefante com diferentes níveis de jaca em função dos horários de incubação.

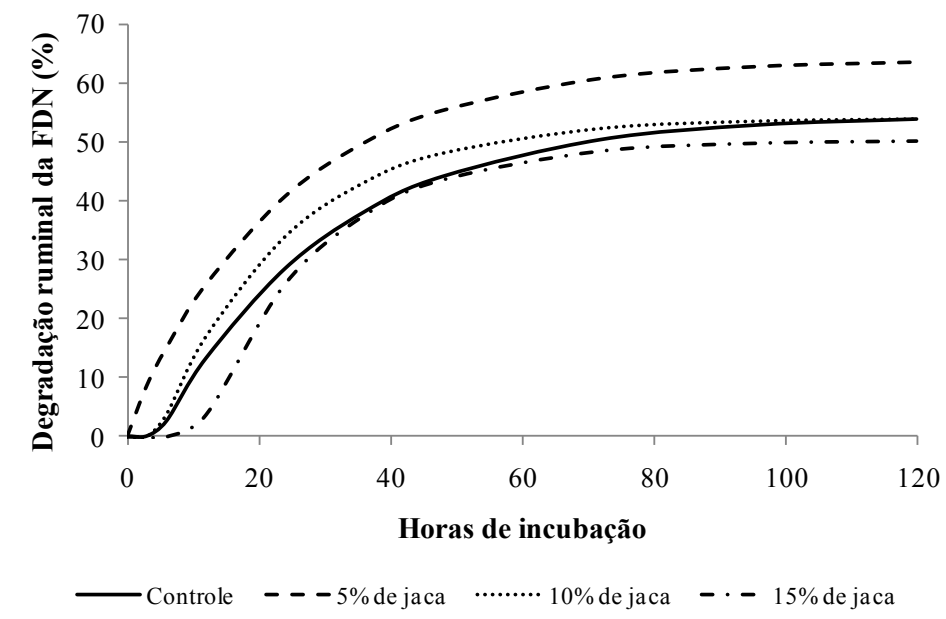

Fonte: Elaboração dos autores.

Estas melhorias observadas na degradação da FDN, em sua maior parte oriunda da FDN do capim elefante, se devem às características da jaca, que apresenta maior concentração de carboidratos solúveis, em detrimento de carboidratos estruturais. Pereira et al. (2007) observaram em jacas in natura, conteúdos de FDN próximos de $27 \%$, e para a FDA, de 15\%. A concentração de carboidratos solúveis da jaca é de $41,32 \%$ e do capim elefante, de 6,55. Assim, a inclusão dos níveis de 5, 10 e $15 \%$ aumentou para 8,$33 ; 11,16$ e $14,44 \%$, o teor de carboidratos solúveis dos tratamentos em relação ao controle (SANTOS et al., 2008).

Segundo Fahey e Berger (1980), o principal fator que afeta a digestão dos carboidratos estruturais é a adição de carboidratos solúveis por meio de alimentos concentrados, que provocam alterações no ambiente do trato digestivo e na cinética do processo digestivo, tais como as taxas de digestão e passagem das partículas, o $\mathrm{pH}$ ruminal e a natureza da população microbiana. Estudos nos quais foram avaliadas as inclusões de carboidratos solúveis na forma de sacarose e melaço, demonstraram melhorias na degradação da fração fibrosa das silagens de milho e alfafa, e foram relacionadas com o aumento da eficiência de uso do nitrogênio e consequentemente com o aumento da síntese de proteína microbiana, pois o aumento no consumo de energia oriunda dos açucares promoveu aumento na eficiência da síntese microbiana (BRODERICK et al., 2004, 2008).

O comportamento quadrático $(\mathrm{P}<0,05)$ da fração indigestível acompanhou o do lag time, com reduções no primeiro nível de inclusão da jaca e aumentos nos dois níveis seguintes. A associação deste comportamento torna-se complementar, uma vez que o aumento no tempo de colonização pode reduzir a extensão da degradação da fibra (LARDY et al., 2004), e por conseguinte aumentar a fração indigestível (Tabela 3).

Tabela 3. Equações de regressão e coeficientes de determinação $\left(\mathrm{R}^{2}\right)$ para a fração potencialmente degradável (B, \%), indigestível (I, \%), taxa de degradação (c, \%/hora), Lag time (Lag, hora) e degradabilidade efetiva (DE) a 2, 5 e $8 \%$ por hora (DE2\%, DE5\% e $\mathrm{DE} 8 \%)$ em função dos níveis de jaca (x).

\begin{tabular}{lcc}
\hline & Equações de regressão & $\mathrm{R}^{2}$ \\
\hline $\mathrm{B}$ & $\hat{\mathrm{Y}}=53,113+0,2941 \mathrm{x}$ & 0,57 \\
$\mathrm{I}$ & $\hat{\mathrm{Y}}=44,231-1,5453 \mathrm{x}+0,133 \mathrm{x}^{2}$ & 0,65 \\
$\mathrm{C}$ & $\hat{\mathrm{Y}}=0,0377+0,0011 \mathrm{x}$ & 0,70 \\
Lag & $\hat{\mathrm{Y}}=5,44-0,7625 \mathrm{x}+0,0621 \mathrm{x}^{2}$ & 0,98 \\
DE2\% & $\hat{\mathrm{Y}}=47,75$ & 0,64 \\
DE5\% & $\hat{\mathrm{Y}}=40,77$ & 0,91 \\
DE8\% & $\hat{\mathrm{Y}}=34,91$ & 0,96 \\
\hline
\end{tabular}

Fonte: Elaboração dos autores. 
Não houve efeito da inclusão de aditivos na ensilagem do capim elefante sobre a degradabilidade efetiva $(\mathrm{P}>0,05)$, apresentando intercepto em 47,$7 ; 40,7$ e $34,9 \%$ para as taxas de passagem de 2,5 e $8 \% / \mathrm{h}$, respectivamente. Estes valores são superiores aos encontrados por Rezende, Paiva e Barcelos (2007) que relataram valores de 23,4\% para degradabilidade efetiva da FDN a $5 \% / \mathrm{h}$ em silagem de capim Napier. Estes pesquisadores trabalharam com capim Napier aos 130 dias de rebrota, o que possivelmente promoveu a menor digestibilidade da fração fibrosa, refletindo em reduções mais acentuadas na degradabilidade efetiva, quando comparado com o presente trabalho, no qual a planta foi colhida jovem (50 dias de rebrota).

Segundo Santos et al. (2008), a ensilagem de capim elefante com diferentes níveis de jaca aumentou a recuperação de matéria seca (RMS) e reduziu as perdas por gases, de forma quadrática, no qual o menor valor de perdas por gases e maior de RMS foi observado no menor nível de inclusão de jaca, o que sugere que níveis mais altos fornecem um excesso de carboidratos solúveis que pode ser utilizado por microrganismos que se desenvolvem em meios com pH muito reduzido e elevada quantidade de açúcares residuais, como é o caso de algumas espécies de leveduras (PAHLOW et al., 2003).

Diante do estudo desenvolvido por Santos et al. (2008), citado anteriormente, e no possível consumo de carboidratos solúveis em excesso, por leveduras, o aumento nas frações indigestíveis das silagens com 10 e $15 \%$ de jaca e no tempo de colonização das partículas de alimento, podem estar associadas as reduções na qualidade da fermentação da silagem nestes dois últimos tratamentos. É possível observar como resposta na melhoria da fermentação da silagem com $5 \%$ de jaca, a melhor extensão de degradação por meio das curvas plotadas na Figura 1, no qual se percebe claramente a redução no tempo de colonização.
A adição de raspa de mandioca aumentou linearmente a fração potencialmente degradável (B) da FDN $(\mathrm{P}<0,05)$, o que fez com que a fração indigestível também fosse significativamente reduzida (Tabela 4). O aumento na fração B com a adição de raspa de mandioca pode ter sido ocasionado pelo seu elevado teor de carboidratos solúveis (ZANINE et al., 2010), como explicitado para a jaca. Além disso, a raspa de mandioca apresenta baixas concentrações de FDN, lignina e consequentemente menor participação da fração indigestível nos carboidratos totais (ANDRADE et al., 2010; OLIVEIRA et al., 2010; VALADARES FILHO; PAULINO; MAGALHÃES, 2010; ZANINE et al., 2010). Desta forma, a inclusão deste alimento ao capim elefante no momento da ensilagem proporcionou maior disponibilidade de carboidratos fibrosos digestíveis, aumentando a fração B e diminuindo a fração I.

A taxa de degradação apresentou comportamento quadrático $(\mathrm{P}<0,05)$, com ligeira redução nos primeiros níveis culminando em $4,45 \% / \mathrm{h}$ no maior nível de raspa de mandioca. Diversos estudos demonstraram que dietas com elevado teor de carboidratos não fibrosos (CNF), principalmente na forma de amido, podem apresentar redução na taxa de degradação da fibra (GONÇALVES et al., 2001; COSTA et al., 2008), principalmente pela redução do pH ruminal (RUSSELL; DOMBROWSKI, 1980; MOULD; ØRSKOV, 1983; HADDAD;GRANT, 2000; MOURIÑO; AKKARAWONGSA; WEIMER, 2001), ou ainda pela inibição da atividade de enzimas fibrolíticas, fato que parece estar associado à liberação de compostos pelas bactérias que degradam o amido (EL-SHAZLY; DEHORITY; JOHSON, 1961), os quais parecem ser de natureza protéica (bacteriocinas) (PIWONKA; FIRKINS, 1993; KALMOKOFF; BARTLETT; TEATHER, 1996). No entanto, observou-se um aumento na taxa de degradação no maior nível de raspa de mandioca, o que contraria o comportamento observado nos menores níveis, onde a taxa de degradação diminuiu. 
De acordo com a Tabela 4 e a Figura 2, a inclusão de raspa de mandioca ocasionou uma diminuição de forma linear $(\mathrm{P}<0,05)$ no lag time das silagens de capim elefante, o que está diretamente relacionado à diminuição do teor de carboidratos fibrosos. Para o início da degradação do alimento no rúmen, o primeiro passo é a aderência da célula bacteriana ao alimento (WEIMER, 1996), a qual ocorre inicialmente através da adesão não específica (interações aniônicas, hidrofóbicas e forças de Van Der Walls), seguida da interação específica entre receptores na superfície da partícula e moléculas denominadas adesinas (presentes na superfície externa da bactéria) e formação de colônias bacterianas ou biofilmes (MIRON; BENGHEDALIA; MORRISON, 2001), definidos como matrizes compactas de populações bacterianas aderidas entre si e a superfície da partícula (KOZLOSKI, 2009). Consequentemente, tecidos mais lignificados apresentam maior resistência à colonização e degradação e no presente trabalho (Tabela 4 e Figura 2) essa resistência foi atenuada com a inclusão da raspa de mandioca.

Este comportamento observado para o lag time pode apresentar variações, uma vez que o coeficiente de determinação da equação de regressão ajustada foi baixo $(0,25)$. Independente do alimento, o processo de mastigação durante a ruminação pode facilitar a hidratação das partículas além de romper barreiras físicas, facilitando a colonização microbiana (KOZLOSKI, 2009). No entanto, em estudos in situ este efeito não é levado em consideração, pois as amostras são colocadas diretamente no rúmen e lá permanecem até o tempo de retirada específico.

A utilização da jaca e da raspa de mandioca como aditivos na ensilagem do capim elefante foi inicialmente avaliada no intuito de fornecer carboidratos solúveis para melhorar o perfil fermentativo e reduzir as perdas no momento em que este capim encontrava-se com elevado valor nutritivo (SANTOS et al., 2008; ZANINE et al., 2010). Estes objetivos foram alcançados e alem disso, como constatado no presente trabalho, os aditivos promoveram aumento na degradação ruminal da fibra, ou seja, no valor nutritivo das silagens. Para uma avaliação mais completa desses alimentos tornam-se necessárias avaliações de consumo, digestibilidade e desempenho com animais ruminantes, pois pouco adianta melhorar o valor nutritivo do alimento se este não é aceitável pelos animais.

Tabela 4. Equações de regressão e coeficientes de determinação $\left(\mathrm{R}^{2}\right)$ para a fração potencialmente degradável (B, \%), indigestível (I, \%), taxa de degradação (c, \%/hora), Lag time (Lag, hora) e degradabilidade efetiva (DE) a 2,5 e $8 \%$ por hora (DE2\%, DE5\% e DE8\%) em função dos níveis de raspa de mandioca (x).

\begin{tabular}{lcc}
\hline & Equações de regressão & $\mathrm{R}^{2}$ \\
\hline $\mathrm{B}$ & $\hat{\mathrm{Y}}=50,142+0,2679 \mathrm{x}$ & 0,53 \\
$\mathrm{I}$ & $\hat{\mathrm{Y}}=45,547-0,3011 \mathrm{x}$ & 0,83 \\
$\mathrm{C}$ & $\mathrm{y}=0,0348-0,00031 \mathrm{x}+0,0002 \mathrm{x}^{2}$ & 0,48 \\
Lag & $\hat{\mathrm{Y}}=5,0325-0,0722 \mathrm{x}$ & 0,25 \\
DE2\% & $\hat{\mathrm{Y}}=45,374$ & 0,57 \\
DE5\% & $\hat{\mathrm{Y}}=39,19$ & 0,51 \\
DE8\% & $\hat{\mathrm{Y}}=33,98$ & 0,43 \\
\hline
\end{tabular}

Fonte: Elaboração dos autores. 
Figura 2. Degradação ruminal in situ da fibra em detergente neutro (FDN) da silagem de capim elefante com diferentes níveis de raspa de mandioca (RM) em função dos horários de incubação.

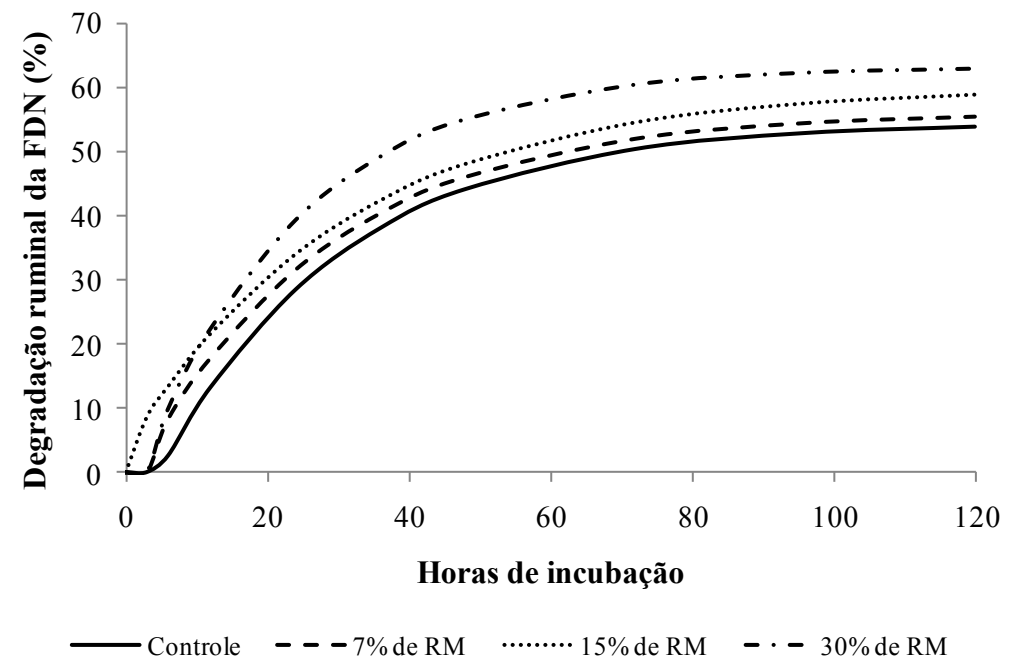

Fonte: Elaboração dos autores.

\section{Conclusões}

A inclusão de jaca desidratada e raspa de mandioca às silagens de capim elefante promovem o aumento da fração potencialmente degradável da fibra e a redução da fração indigestível.

\section{Referências}

ANDRADE, I. V. O.; PIRES, A. J. V.; CARVALHO, G. G. P.; VELOSO, C. M.; BONOMO, P. Fracionamento de proteína e carboidratos em silagens de capim-elefante contendo subprodutos agrícolas. Revista Brasileira de Zootecnia, Viçosa, v. 39, n. 11, p. 2342-2348, 2010.

ANDRADE, S.; MELOTTI, J.; LAÉRCIO, T. Effect of some additives on the quality o elephant grass (Pennisetum purpureum Schum) silage. Brazilian Journal of Veterinary Research Animal Science, São Paulo, v. 41, n. 6, p. 409-415, 2004.

BRODERICK, G. A.; LUCHINI, N. D.; REYNAL, S. M.; VARGA, G. A.; ISHLER, V. A. Effect on production of replacing dietary starch with sucrose in lactating dairy cows. Journal of Dairy Science, Champaign, v. 91, n. 12, p. 4801-4810, 2008.

BRODERICK, G. A.; RADLOFF, W. J. Effect of molasses supplementation on the production of lactating dairy cows fed diets based on alfalfa and corn silage. Journal of Dairy Science, Champaign, v. 87, n. 9, p. 2997-3009, 2004.
COSTA, V. A. C.; DETMANN, E.; VALADARES FILHO, S. C.; PAULINO, M. F.; HENRIQUES, L. T.; MANTOVANI, H. C. Degradação in vitro da fibra em detergente neutro de forragem tropical de baixa qualidade em função de suplementação com proteína e/ ou carboidratos. Revista Brasileira de Zootecnia, Viçosa, v. 37, n. 3, p. 494-503, 2008.

EL-SHAZLY, K.; DEHORITY, B. A.; JOHSON, R. R. Effect of starch on the digestion of cellulose in vitro and in vivo by rumen microorganisms. Journal of Animal Science, Champaign, v. 20, n. 1, p. 268-273, 1961.

FAHEY, G. C.; BERGER, L. L. Los carbohidratos en la nutrición de los rumiantes. In: CHURCH, D. C. (Ed.). El rumiante. Fisiologia digestiva y nutrición. Zaragoza: Acribia, 1980. p. 305-338.

GONÇALVES, A. L.; LANA, R. P.; RODRIGUES, M. T.; VIEIRA, R. A. M. V.; QUEIROZ, A. C.; HENRIQUE, D. S. Degrabilidade ruminal da matéria seca e da fibra em detergente neutro de alguns volumosos utilizados na alimentação de cabras leiteiras, submetidas a dietas com diferentes relações volumoso:concentrado. Revista Brasileira de Zootecnia, Viçosa, v. 30, n. 6, p. 18931903, 2001.

HADDAD, S. G.; GRANT, R. J. Influence of nonfibre carbohydrate concentration on forage fibre digestion in vitro. Animal Feed Science and Technology, Amsterdam, v. 86, n. 1-2, p. 107-115, 2000.

KALMOKOFF, M. L.; BARTLETT, F.; TEATHER, R. M. Are ruminal bacteria armed with bacteriocins? Journal of Animal Science, Champaign, v. 79, n. 12, p. 2297-2306, 1996. 
KOZLOSKI, G. V. Bioquímica dos ruminantes. 2. ed. Santa Maria: Ed. UFSM, 2009. 216 p.

LARDY, G. P.; ULMER, D. N.; ANDERSON, V. L.; CATON, J. S. Effects of increasing level of supplemental barley on forage intake, digestibility, and ruminal fermentation in steers fed medium-quality grass hay. Journal of Animal Science, Champaign, v. 82, n. 12, p. 3662-3668, 2004.

MERTENS, D. R.; LOFTEN, J. R. The effect of starch on forage fiber digestion kinetics in vitro. Journal of Dairy Science, Champaign, v. 63, n. 9, p. 1437-1446, 1980.

MIRON, J.; BEN-GHEDALIA, D.; MORRISON, M. Invited review: adhesion mechanisms of rumen cellulolytic bacteria. Journal of Dairy Science, Champaign, v. 84, n. 6, p. 1294-1309, 2001.

MOULD, F. L.; ØRSKOV, E. R. Manipulation of rumen fluid $\mathrm{pH}$ and its influence on cellulolysis in sacco, dry matter degradation and the rumen microflora of sheep offered either hay or concentrate. Animal Feed Science and Technology, Amsterdam, v. 10, n. 1, p. 1-14, 1983.

MOURIÑO, F.; AKKARAWONGSA, R. A.; WEIMER, P. J. Initial $\mathrm{pH}$ as a determinant of cellulose digestion rate by mixed ruminal microorganisms in vitro. Journal of Dairy Science, Champaign, v. 84, n. 4, p. 848-859, 2001.

OLIVEIRA, J. B.; PIRES, A. J. V.; CARVALHO, G. G. P.; RIBEIRO, L. S. O.; CRUZ, J. F.; SILVA, F. F. Subprodutos industriais na ensilagem de capimelefante para cabras leiteiras: consumo, digestibilidade de nutrientes e produção de leite. Revista Brasileira de Zootecnia, Viçosa, v. 39, n. 2, p. 411-418, 2010.

PAHLOW, G.; MUCK, R. E.; DRIEHUIS, F.; OUDE ELFERINK, S. J. W. H.; SPOELSTRA, S. F. Microbiology of ensiling. In: SILAGE SCIENCE AND TECHNOLOGY, 42., 2003. Madison, USA. Proceedings... Madison: ASCSSA-SSSA. 2003. p. 31-93.

PEREIRA, L. G. R.; MAURÍCIO, R. M.;AZEVÊDO, J.A. G.; OLIVEIRA, L. S.; BARREIROS, D. C.; FERREIRA, A. L.; BRANDÃO, L. G. N.; FIGUEIREDO, M. P. Composição bromatológica e cinética de fermentação ruminal in vitro da jaca dura e mole (Artocarpus heterophyllus). Livestock. Research. Rural Development, Cali, v. 19, n. 3, Article 45, 2007.

PIWONKA, E. J.; FIRKINS, J. L. Effect of glucose fermentation on fiber digestion by ruminal microorganisms in vitro. Journal of Dairy Science, Champaign, v. 79, n. 12, p. 2196-2206, 1993.
REZENDE, V. M.; PAIVA, P. C. A.; BARCELOS, A. F. Degradabilidade ruminal das silagens de capim-napier produzidas com diferentes níveis de farelo de "batata diversa". Ciência e Agrotecnologia, Lavras, v. 31, n. 2, p. 485-491, 2007.

RUSSELL, J. B.; DOMBROWSKI, D. B. Effect of pH on the efficiency of growth by pure cultures of rumen bacteria in continuous culture. Applied and Environmental Microbiology, Washington, v. 39, n. 3, p. 604-610, 1980.

SANTOS, E. M.; ZANINE, A. M.; DANTAS, P. A. S.; DÓREA, J. R. R.; SILVA, T. C.; PEREIRA, O. G.; LANA, R. P.; COSTA, R. G. Composição bromatológica, perdas e perfil fermentativo de silagens de capim-elefante com níveis de inclusão de jaca. Revista Brasileira de Saúde e Produção Animal, Salvador, v. 9, n. 1, p. 64-73, 2008.

SANTOS, E. M.; ZANINE, A. M.; FERREIRA, D. J.; OLIVEIRA, J. S.; PEREIRA, O. G.; ALMEIDA, J. C. C. Efeito da adição do soro de queijo sobre a composição bromatológica, fermentação, perdas e recuperação de matéria seca em silagem de capim-elefante. Ciência Animal Brasileira, Goiânia, v. 7, n. 2, p. 235-239, 2006.

SAS Institute Inc. System for microsoft windows, Release 9.1, Cary, 2003. 2003. CD-ROM.

SILVA, D. J.; QUEIROZ, A. C. Análise de alimentos: métodos químicos e biológicos. 3. ed. Viçosa: Impr. Universitária, 2002. 235 p.

VALADARES FILHO, S. de C.; PAULINO, P. V. R.; MAGALHÃES, K. A. Exigências nutricionais de zebuínos e tabelas de composição de alimentos/BRCORTE. Viçosa: UFV, 2006b. 142 p.

VAN SOEST, P. J.; ROBERTSON, J. B. Analysis of forages and fibrous foods. Ithaca: Cornell University, 1985. $202 \mathrm{p}$.

WEIMER, P. J. Why don't ruminal bacteria digest cellulose faster? Journal of Dairy Science, Champaign, v. 79, n. 8, p. 1496-1502, 1996.

ZANINE, A. M.; SANTOS, E. D.; FERREIRA, D. J.; OLIVEIRA, J. S.; PEREIRA, O. G. Avaliação da silagem de capim-elefante com adição de farelo de trigo. Archivos de Zootecnia, Córdoba, v. 55, n. 209, p. 75-84, 2006.

ZANINE, A. M.; SANTOS, E. M.; DÓREA, J. R. R.; DANTAS, P. A. S.; SILVA, T. C.; PEREIRA, O. G. Evaluation of elephant grass silage with the addition of cassava scrapings. Revista Brasileira de Zootecnia, Viçosa, v. 39, n. 12, p. 2611-2616, 2010. 